\title{
Analysis of the Factors Affecting the
}

\section{Employment Quality of University Graduates}

\section{by DEMATEL / ISM Method}

\author{
Wei Wang ${ }^{1}$, Jian $\mathrm{Liu}^{1}$, Shubing Qiu ${ }^{2 *}$ \\ ${ }^{1}$ Wuhu Institute of Technology, \\ Wuhu 241000, \\ China \\ ${ }^{2}$ Anhui Polytechnic University, \\ Wuhu 241000, \\ China
}

Received: February 23, 2021. Revised: July 19, 2021. Accepted: August 3, 2021. Published: August 5, 2021.

\begin{abstract}
To analyze how to improve the employment quality of university graduates and clarify the internal logical relationship between the influencing factors in the employment quality of university students through analyzing of the influencing factors on the employment quality of university students Based on the integrated DEMATEL / ISM method. Commuters are assumed used DEMATEL method and Hierarchical structure model of influencing factors on employment quality of university graduates constructed by ISM for obtaining the influence degree. Describe the causal relationship of the factors affecting the employment quality of university
\end{abstract}

graduates, hierarchical logical structure of factors affecting university graduate employment quality. The results show that the employment recommendation service and subsidy of government, cooperation of university and enterprise, vocational planning and education of university, employee Brand construction of enterprise, independent's employment willingness are the direct factors that effect the employment quality of college students, and should be given $\begin{array}{llllllllllllllllll}\mathbf{p} & \mathbf{r} & \mathbf{i} & \mathbf{0} & \mathbf{r} & \mathbf{i} & \mathbf{t} & \mathbf{y} & & \mathbf{a} & \mathbf{t} & \mathbf{t} & \mathbf{e} & \mathbf{n} & \mathbf{t} & \mathbf{i} & \mathbf{o} & \mathbf{n}\end{array}$ Keywords - DEMATEL, ISM, Employment quality, Graduate, Influence factor. 


\section{I . INTRODUCTION}

HE employment rate of college students has been $T_{\text {the }}$ ont the only indicator of employment in colleges and universities for a long time. After 2014, Chinese colleges and universities began to release annual reports on employment quality. The employment evaluation of college students changed from a single evaluation on employment rate to an evaluation on employment quality.

The employment rate, professional matching rate, salary and resignation rate were analyzed as factors to describe the employment quality of college graduates. The government has continuously issued encouraging and supporting policies, colleges and universities have continuously increased employment services for college students, and all sectors of society have made joint efforts to improve the employment quality of college students.

Di Pietro measured the quality of talent training in colleges and universities through employment performance indicators and puts forward employment counterparts [1]. Mavromaras once pointed out that employment mismatch directly affects employment quality [2]. Dai Mao and others pointed out that it is not that college students can't find a job, but it is difficult to find a satisfactory job. There are salary, professional counterparts and other indicators to achieve high-quality employment [3], In the third-party employment quality survey, Max took the employment rate, employment counterpart rate and other indicators as the parallel indicators of employment quality for the first time [4]. $\mathrm{Wu}$ Xinzhong proposed that the elements for evaluating employment quality are diverse and complex [5], and used the comprehensive evaluation method to evaluate employment quality [6]. Zhao Ming proposed the relationship between employment quality and employment expectation, and found career orientation through career planning [7], Zhang Rui combed the indicators of employment quality and pointed out the influencing factors [8]. Shi Shutao and others analyzed the impact of policies on employment quality from the perspective of public management [9]. Throughout the literature, The present college students employment quality study has more research on the comprehensive evaluation of employment quality, research is mainly distributed in the employment quality evaluation index, the weight coefficient of employment quality evaluation and employment quality evaluation model of three aspects, while research in the impacting factors of university students' employment quality is relatively insufficient, it only uses statistical methods of employment quality factors investigation but hasn't further analysis the inner mechanism of the influence factors of university students' employment quality. It does not point out which are the main forming factors, nor does it study the relationship between the factors affecting the employment quality of college students.

In view of this, this paper constructed the index system of influencing factors on the quality of the college student employment through DEMATAL and described the factors influencing the quality of university students' employment, as well as the relationship between various factors. It built the hierarchical relation model by the ISM which described the structure of the factors influencing the quality of university students' employment level and showed the employment quality of ascension path. To solve the problem that the evaluation of college students' employment quality has a result but no improvement path, 
so as to provide some Suggestions for improving the quality of college students' employment.

\section{II . ESTABLISHMENT OF AN INDEX SYSTEM FOR}

\section{UNIVERSITY GRADUATE’ EMPLOYMENT QUALITY FACTORS}

A. Influencing mechanism of college students' employment quality factors

The employment of college students is the sum of a series of activities in the process of supply-demand balance between the demand of enterprise talents and the demand of students' career development, and the Government, enterprises, universities and college students are the main participants in employment activities.

In the employment system of college students, in order to solve the employment demand of enterprises and the employment service of universities, the government, in combination with universities, establishes a recruitment platform, and provides employment subsidies to graduates, enterprises and universities to promote the employment of college students. Through school enterprise cooperation, the school realizes the goal of talent training, improves employment services through career planning education and vocational skills training, the enterprises can attract graduates through the construction of employer brand and the provision of post development space, for the government, it mainly provides macro policy guidance, and the government factor, enterprise factor, university factor and college student factor are four important factors in the employment system of college students, and all the four factors will directly affect the quality of employment.

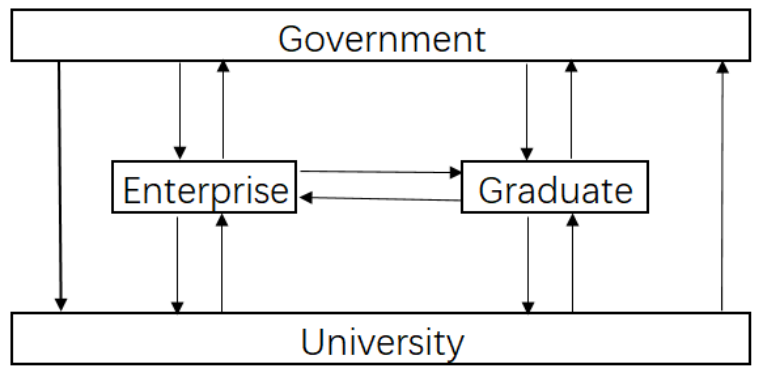

Figure 1 Index system of factors affecting employment quality of university graduates

B. Factors influencing college students' employment quality

Based on the analysis of the influencing mechanism of university graduate' employment quality factors. According to the analysis of employment work and some specific standards of employment work, the influencing factors are classified and analyzed, and several sub-factors are obtained, as shown in Table 1.

Table 1 The factors affecting the employment quality of college students

\begin{tabular}{|c|c|c|c|}
\hline $\begin{array}{l}\text { Serial } \\
\text { Number }\end{array}$ & Symbol & Major Factor & Sub Factor \\
\hline 1 & $\mathrm{~F}_{1}$ & $\begin{array}{l}\text { Government employment } \\
\text { referral service }\end{array}$ & $\begin{array}{l}\text { Job search platform construction, job recommendation } \\
\text { services, etc. }\end{array}$ \\
\hline 2 & $\mathrm{~F}_{2}$ & $\begin{array}{l}\text { Government employment } \\
\text { subsidy }\end{array}$ & Subsidies for companies, subsidies for students, etc. \\
\hline
\end{tabular}




\begin{tabular}{|c|c|c|c|}
\hline 3 & $\mathrm{~F}_{3}$ & $\begin{array}{l}\text { University-enterprise } \\
\text { Cooperation }\end{array}$ & Order training, joint training, etc. \\
\hline 4 & $\mathrm{~F}_{4}$ & $\begin{array}{l}\text { Career Planning } \\
\text { education in colleges }\end{array}$ & Career planning education and consulting services, \\
\hline 5 & $\mathrm{~F}_{5}$ & $\begin{array}{l}\text { Vocational training in } \\
\text { universities }\end{array}$ & Technical training and skills certificates, etc. \\
\hline 6 & $\mathrm{~F}_{6}$ & Employer branding & Recruitment image, entry image, etc. \\
\hline 7 & $\mathrm{~F}_{7}$ & $\begin{array}{l}\text { Job development space } \\
\text { for enterprises }\end{array}$ & Development prospects, post development paths, etc. \\
\hline 8 & $\mathrm{~F}_{8}$ & Workplace fitness & $\begin{array}{l}\text { The ability of university graduates to organize, respond, } \\
\text { etc. }\end{array}$ \\
\hline 9 & $\mathrm{~F}_{9}$ & Employment willingness & Clarity, intensity, etc. \\
\hline
\end{tabular}

confirm the order of improvement factors [14].

\section{ANALYTICAL MODEL OF FACTORS AFFECTING THE}

\section{EMPLOYMENT QUALITY OF UNIVERSITY GRADUATES}

\section{A. DEMATEL and ISM}

DEMATEL is the abbreviation of Decision Making Trial and Evaluation Laboratory, which is generally called the Decision Trial and Evaluation Laboratory Method [10]. This method is an analysis tool proposed by A. Gabus \& E. Fontela, which is used to describe the relationship between element structures in complex systems. For it, the first step is to establish the logical relationship of the elements in the direct description matrix description system, and calculate the influence degree and affected degree of each element through matrix calculation [11]. The second step is to establish a direct impact matrix based on the logical relationship of each element in the system, and then to build the impact relationship structure diagram by calculating the degree of influence of each element [12], and to calculate whether the result is greater or less than 0 according to the cause degree, and classify the impact factors as cause factors and result factors [13]. After that, calculate the centrality, describe its importance, and
For the Interpretive Structure Modeling (ISM). It is a method proposed by Professor J. Warfield to analyze the system structure and divide complex and messy system elements into clear multi-layer structures. By setting the problem and describing the nodes and directed edges, the adjacency matrix is established and the reachability matrix is calculated to determine the hierarchical distribution. Finally, an interpretive structure model is formed.

Compared with the reachability matrix in ISM method, the comprehensive influence matrix in DEMATEL method can not only reflect the existence of the action relationship between factors, but also reflect the action degree. Therefore, by introducing the unit matrix, the comprehensive influence matrix is transformed into the overall influence matrix, and a certain calculation method is used to convert the overall influence matrix into the reachability matrix, so as to realize the integration of the two methods, It can not only quantitatively calculate the importance of influencing factors on College Students' employment quality and identify key elements, but also clarify the direct and fundamental factors of College Students' 
employment quality by dividing levels, so as to provide reference for formulating countermeasures to improve college students' employment quality.

\section{Construction of analysis model affecting college} students' Employment Quality

The research ideas of dematel-ism method are as follows: firstly, DEMATEL method is used to determine the comprehensive influence matrix, calculate the influence degree, affected degree, cause degree, centrality and other indicators reflecting the relationship between various factors in the system, simplify the influencing factors according to the centrality and cause degree, and ignore the unimportant factors; Considering the self influence of factors, after calculating the overall influence matrix, a reasonable correction factor is introduced to further convert it into reachable matrix; The ISM method is used to establish a structural model to reveal the hierarchical relationship of system factors.

The specific implementation model of the analysis model affecting the employment quality of college students is shown as follows:

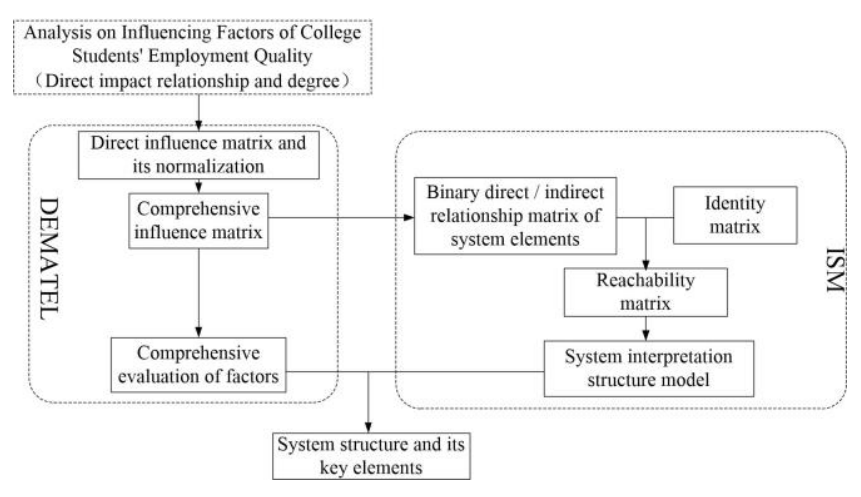

Figure 2 Analysis model diagram of Affecting College Students' Employment Quality

The construction steps of the analysis model affecting the employment quality of college students are as follows:
Step1: The corresponding influencing factors are obtained by analyzing the influencing mechanism of the employment quality factors of university graduates, and the system influencing factors are determined to be Fn $(n=1$, 2 ...n);

Step2: Determine the degree of direct impact on the quality of employment of university graduates;

Step3: Construction of a matrix A that directly affects the quality of college students' employment $\left(A=\left[a_{i j}\right] n \times n\right)$. $\mathrm{A}\left(\mathrm{A}=\left[\mathrm{a}_{\mathrm{ij}}\right] \mathrm{n} \times \mathrm{n}\right)$ is a direct influence matrix, and the content of a directed graph of mutual influence of factors is expressed in a matrix form, where aij is the influence of factor $\mathrm{i}$ on factor $\mathrm{j}$. If factor $\mathrm{i}$ has no effect on factor $\mathrm{j}$, then $\mathrm{a}_{\mathrm{ij}}=0$.

$$
A=\left[\begin{array}{ccc}
0 & \cdots & a 1 \mathrm{n} \\
\vdots & \ddots & \vdots \\
a \mathrm{n} 1 & \cdots & 0
\end{array}\right] \operatorname{aij}(\mathrm{i}=1,2 \ldots \ldots \mathrm{n}, \mathrm{j}=1,2 \ldots \ldots \mathrm{n}, \mathrm{ij}) \text { ifi }=\mathrm{j} \text {, thenaij }
$$

Step4: Calculation normalization directly affects the matrix. Such as formula 1:

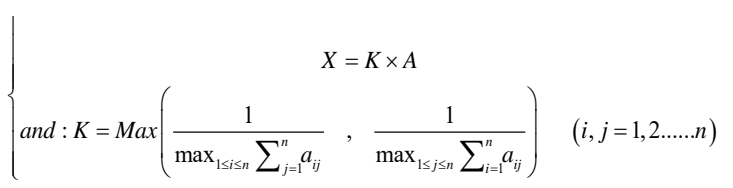

Step5: To determine the comprehensive impact matrix with formula 2:

$$
\left\{\begin{array}{c}
T=X(I-X)^{-1} \\
\text { I is the identity matrix }
\end{array}\right.
$$

Step6: To calculate of influence degree and affected degree of employment quality of university graduates. Di expresses the influence degree of each factor in the matrix T. The specific calculation formula is Equation 3:

$$
\begin{cases}D_{i}=\sum_{j=1}^{n} T_{i j} & (i=1,2,3 \cdots, n) \\ R_{i}=\sum_{j=1}^{n} T_{i j} & (i=1,2,3 \cdots, n)\end{cases}
$$

Step7: To calculate the centrality and cause of employment quality for university students, and $\mathrm{Zn}$ stands 
for the centrality of each factor. The calculation formula is Equation 1.4:

$$
\begin{cases}Z_{n}=D_{i}+R_{j} & (i=j=1,2 \ldots \ldots n) \\ Y_{n}=D_{i}-R_{j} & (i=j=1,2 \ldots \ldots n)\end{cases}
$$

Step8: To calculate the overall impact matrix $H$ of the employment quality system for college students $(H=($ hij $) n$ $\times \mathrm{m})$ :

$$
\mathrm{H}=\mathrm{T}+\mathrm{E}
$$

Step9: To determine the reachability matrix $U(U=$ (uij) $n \times n)$ according to the overall influence matrix $H$ of the employment quality system of university students: Set the threshold $\lambda$ according to the actual situation. When uij $\geq \lambda$ $(i=1, \ldots, N ; j=1, \ldots, n)$, take uij $=1$; When uij $<\lambda(i=$ $1, \ldots, n ; j=1, \ldots, n)$, take uij $=0$.

Step10: Determine the reachable set $\mathrm{Ri}$ of each factor and the preceding set $\mathrm{Ai}$.

Step11: Calculate the reachable set $\mathrm{Ri}$, the antecedent set $\mathrm{Ai}$, the common set $\mathrm{Ci}$, the starting set $\mathrm{B}$, and the ending set E.

Step12: Repeat steps 10 and 11 until all factors are crossed out.

Step13: Establish a hierarchical structure of factors in the order in which they are removed.

\section{EMPIRICAL ANALYSES OF FACTORS AFFECTING THE}

\section{EMPLOYMENT QUALITY OF COLLEGE STUDENTS}

According to the factor system table (Table 1) that affects the employment quality of college students, the "0-4" 5-level scale method is used, and its correlation strength is represented by $0,1,2,3$, and 4 , which in turn represent "extremely strong impact, strong Impact, moderate impact, weak impact, no impact [15]. Based on discussion and analysis and extensive consultation with peers in the industry to determine the relationship between factors, establish a direct impact matrix A, use formula (1) to obtain a standardized matrix $X$, and then use MATHEMATICA software to calculate the comprehensive impact through formula (2) Matrix T, and then calculate the cause degree $\mathrm{Y}$ and center degree $\mathrm{Z}$ of each influencing factor by the formulas (3) and (4) as shown in Table 2. The seventh step is to make a graph according to the centrality and cause of the factors, mark the position of each factor on the coordinate system, and analyze the importance of each factor.

$$
A=\left[\begin{array}{lllllllll}
0 & 0 & 0 & 0 & 0 & 0 & 4 & 3 & 0 \\
0 & 0 & 0 & 0 & 0 & 3 & 0 & 0 & 0 \\
0 & 0 & 0 & 0 & 0 & 0 & 0 & 0 & 4 \\
0 & 3 & 0 & 0 & 0 & 0 & 3 & 0 & 0 \\
0 & 0 & 0 & 0 & 0 & 0 & 0 & 2 & 0 \\
0 & 0 & 0 & 2 & 0 & 0 & 0 & 3 & 0 \\
0 & 0 & 0 & 0 & 3 & 0 & 0 & 4 & 0 \\
0 & 0 & 0 & 0 & 0 & 0 & 0 & 0 & 0 \\
0 & 0 & 0 & 0 & 0 & 0 & 3 & 0 & 0
\end{array}\right]
$$

$$
T=\left[\begin{array}{ccccccccc}
0 & 0 & 0 & 0 & 0.245 & 0 & 0.571 & 0.825 & 0 \\
0 & 0.055 & 0 & 0.129 & 0.024 & 0.452 & 0.055 & 0.232 & 0 \\
0 & 0 & 0 & 0 & 0.105 & 0 & 0.245 & 0.170 & 0.571 \\
0 & 0.452 & 0 & 0.055 & 0.194 & 0.194 & 0.452 & 0.397 & 0 \\
0 & 0 & 0 & 0 & 0 & 0 & 0 & 0.286 & 0 \\
0 & 0.129 & 0 & 0.302 & 0.055 & 0.055 & 0.129 & 0.542 & 0 \\
0 & 0 & 0 & 0 & 0.429 & 0 & 0 & 0.694 & 0 \\
0 & 0 & 0 & 0 & 0 & 0 & 0 & 0 & 0 \\
0 & 0 & 0 & 0 & 0.184 & 0 & 0.429 & 0.297 & 0
\end{array}\right]
$$

Table 2 Comprehensive impact relationship table

\begin{tabular}{c|c|c|c|c}
\hline Factor & Influence & Affected & Center Degree & Cause Degree \\
& Degree D & Degree $\mathrm{R}$ & $(\mathrm{D}+\mathrm{R})$ & $(\mathrm{D}-\mathrm{R})$ \\
\hline $\mathrm{F}_{1}$ & 1.64 & 0.00 & 1.64 & 1.64 \\
\hline $\mathrm{F}_{2}$ & 0.95 & 0.64 & 1.59 & 0.31 \\
\hline $\mathrm{F}_{3}$ & 1.09 & 0.00 & 1.09 & 1.09 \\
\hline $\mathrm{F}_{4}$ & 1.74 & 0.49 & 2.23 & 1.26 \\
\hline $\mathrm{F}_{5}$ & 0.29 & 1.24 & 1.52 & -0.95 \\
\hline $\mathrm{F}_{6}$ & 1.21 & 0.70 & 1.91 & 0.51 \\
\hline $\mathrm{F}_{7}$ & 1.12 & 1.88 & 3.00 & -0.76 \\
\hline $\mathrm{F}_{8}$ & 0.00 & 3.44 & 3.44 & -3.44 \\
\hline
\end{tabular}




\begin{tabular}{l|l|l|l|l}
$\mathrm{F}_{9}$ & 0.91 & 0.57 & 1.48 & 0.34 \\
\hline
\end{tabular}

In the above table, $\mathrm{D}$ represents the comprehensive influence degree of this factor on other factors, and $\mathrm{R}$ represents the comprehensive influence degree of this factor by other factors. $\mathrm{D}+\mathrm{R}$ is the centrality of the factor. Centrality is the influence degree with the increase of influence degree. It indicates the position and influence range of the factor in all factors. The greater the centrality value, the greater the role and importance of the factor in the system. D-R is the cause degree of this factor. If it is positive, it means that this factor has a great impact on other factors. If it is negative, it is the result factor, which is greatly affected by other factors [16]. According to the centrality analysis, F8 workplace fitness ranks first, followed by F7 job development space for enterprises. The centrality of other factors is relatively small, which shows that workplace fitness occupies a core position in the comprehensive influence relationship and has an important impact on the good development of the whole system. According to the cause degree analysis, it can be seen from table 2 that in the whole system, F1 government employment reference service has the highest cause degree and has the greatest impact on other factors. Therefore, in order to improve the quality of college students, we must pay attention to the control and development of government employment reference service.

According to Table 2, it can be concluded that the government's employment recommendation service, government's employment subsidy, university-enterprise cooperation, university career planning education, enterprise employer brand building, and individual employment willingness are greater than 0 , which mean they are the reason factors. And the vocational skills training in colleges and universities, the post development space of enterprises, and the employment compatibility are negative, which mean they are the result factors [17].

Among the cause factors, the professional planning education is of the highest degree. Then to describe the centrality and cause of the factors as a curve (as shown in Figure 3), it can be found that the cause and centrality of the school-enterprise cooperation of universities overlap, it indicates that the impact degree of the school-enterprise cooperation of the university is 0 , which is called the root cause of the factors affecting the employment quality of college students, the cause of employment compatibility and the degree of centrality are nearly symmetrical, it indicates that the degree of influence is the smallest and must be caused and affected by other factors [18].

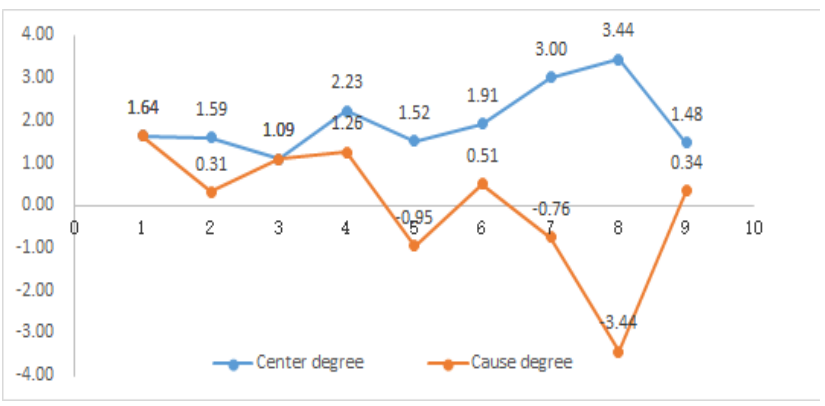

Figure 3 The centrality and reason curve of factors

affecting the quality of employment of college students

The DEMATEL method can analyze the direct and indirect relationships between the factors that affect the quality of employment of college students. However, it can not describe the hierarchical structure and operating mechanism of each influencing factors, so it needs to use the ISM method to analyze the multi-level hierarchical structure. Now to use formula (5) to obtain the overall system impact matrix H. and to follow the steps 9 and 13 above to complete the structural structure flowchart, and to 
establish a hierarchical mechanism model that affects the quality of university's employment.

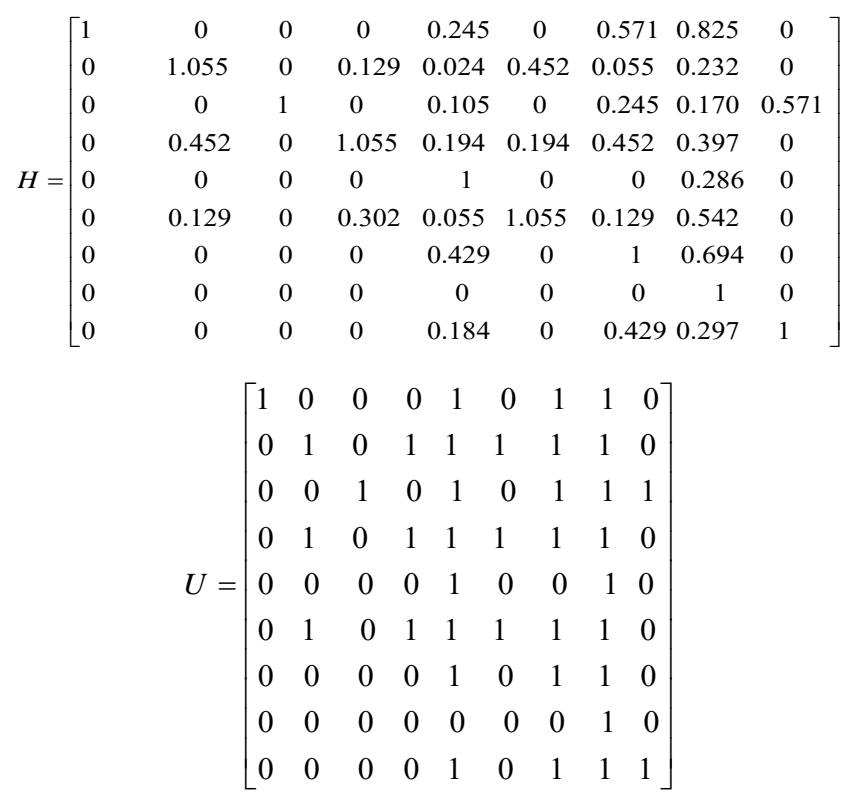

Table 4 Results after extracting F2, F4, F6

\begin{tabular}{ccccc}
\hline & & & $\mathrm{R}$ & \\
& $\mathrm{Ri}(\mathrm{Fi})$ & $\mathrm{A}(\mathrm{Fi})$ & $(\mathrm{Fi}) \cap \mathrm{A}(\mathrm{Fi})$ & \\
\hline 1 & $1,5,7,8$ & 1 & 1 & \\
2 & $3,5,7,8,9$ & 3 & 3 & \\
3 & 5,8 & $1,3,5,7,9$ & 5,8 & \\
4 & $5,7,8$ & $1,3,5,9$ & 7 & \\
5 & 8 & 1,9 & 8 & \\
6 & $5,7,8,9$ & 3,9 & 9 & \\
\hline
\end{tabular}

To analyze the intersection of each row "1" and each column "1", and obtain the reachable set R (Fi), the preceding set $A\left(\mathrm{~F}_{\mathrm{i}}\right)$, and the common set is $\mathrm{R}\left(\mathrm{F}_{\mathrm{i}}\right) \cap \mathrm{A}\left(\mathrm{F}_{\mathrm{i}}\right)$, $\Pi(\mathrm{P})$ As a result of dividing the area, it is: $\Pi(\mathrm{P})=\mathrm{P}_{-}$, $\mathrm{P}_{-} 2 \ldots, \mathrm{P}_{-} \mathrm{k}, \ldots \mathrm{P} \_\mathrm{n} ; \mathrm{P} \_\mathrm{k}$ is the $\mathrm{k}$-th feature set.

$\mathrm{Ln}$ is the level of the set of influencing factors of the entire system. L1, L2, L3, L4 ... Ln $(n=1 \ldots n), n$ is the number of system layers, 1 is the first layer of $\mathrm{L}$, second is L2, and Lk1 is Tier n.

Table 3 Level bit division process

\begin{tabular}{|c|c|c|c|c|}
\hline $\mathrm{Fi}$ & $\mathrm{R}(\mathrm{Fi})$ & $\mathrm{A}(\mathrm{Fi})$ & $\mathrm{R}(\mathrm{Fi}) \cap \mathrm{A}(\mathrm{Fi})$ & $\Pi(P)$ \\
\hline
\end{tabular}

\begin{tabular}{|c|c|c|c|c|}
\hline 1 & $1,5,7,8$ & 1 & 1 & \multirow{9}{*}{$\mathrm{L} 1=\left\{F_{2}, F_{4}, F_{6}\right\}$} \\
\hline \multicolumn{2}{|c|}{$22,4,5,6,7,8$} & $2,4,6$ & $2,4,6$ & \\
\hline 3 & $3,5,7,8,9$ & 3 & 3 & \\
\hline \multicolumn{2}{|c|}{$42,4,5,6,7,8$} & $2,4,6$ & $2,4,6$ & \\
\hline 5 & 5,8 & $1,2,3,4,5,6,7,9$ & 5,8 & \\
\hline & $2,4,5,6,7,8$ & $2,4,6$ & $2,4,6$ & \\
\hline 7 & $5,7,8$ & $1,2,3,4,6,7,9$ & 7 & \\
\hline 8 & 8 & $1,2,3,4,5,6,7,8,9$ & 8 & \\
\hline 9 & $5,7,8,9$ & 3,9 & 9 & \\
\hline
\end{tabular}

According to the conditions of $\mathrm{R}(\mathrm{Fi}) \mathrm{FiA}(\mathrm{Fi})=\mathrm{R}(\mathrm{Fi})$, the levels are extracted. An analysis of the bit division process in Table 3 shows that the three factors F2, F4, and F6 are at the top level of the system, which is the final level of the system. Aims. Then extract all the elements related to F2, F4, and F6 to obtain Table 4. It can be found that F5 and F8 meet the conditions and are extracted. This means that F5 and F8 is the second layer and the reasons for F2, F4, and F6 are the same. The method obtained the results of Table 5 after extracting F5 and F8. It can be found that it is the third time for F1, F3, F7, and F9, and the reason for F5 and F8. The results show that the elements F1, F3, F7, and F9 are the lowest level of the system and are the root causes of the employment quality of college students. The relationship between the layers is shown in Figure 4.

Table 5 Results after extracting F5 and F8

\begin{tabular}{ccccc}
\hline $\mathrm{Fi}$ & $\mathrm{R}(\mathrm{Fi})$ & $\mathrm{A}(\mathrm{Fi})$ & $\mathrm{R}(\mathrm{Fi}) \cap \mathrm{A}(\mathrm{Fi})$ & $\Pi(P)$ \\
\hline 1 & 1,7 & 1 & 1 & \\
2 & $3,7,9$ & 3 & 3 & $\mathrm{Lk} 3=$ \\
4 & 7 & $1,3,9$ & 7 & $\left\{F_{1}, F_{3}, F_{7}, F_{9}\right\}$ \\
6 & 7,9 & 3,9 & 9 & \\
\hline
\end{tabular}




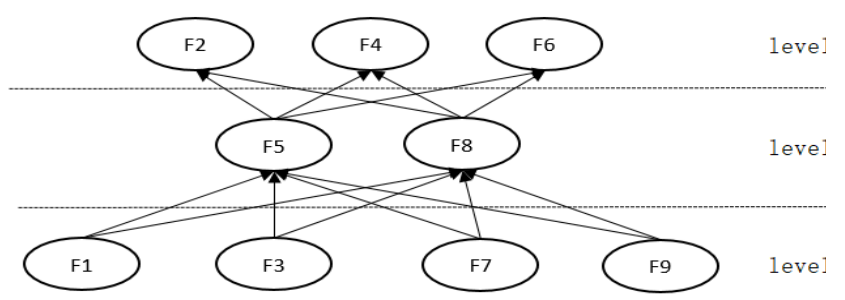

Figure 4 Relationship display of each layer

\section{CONCLUSIONS AND COUNTERMEASURES}

\section{A. Conclusions}

Seen from the above analysis, DEMATEL and ISM have their own advantages and disadvantages. DEMATEL can identify the key elements and the degree of influence, but it cannot divide the structural level and basic elements. Although ISM can divide the system level, it cannot identify the role of the elements [19]. Therefore, the integration of the two can both divide the hierarchical structure of a complex system and identify and evaluate its key elements.

The DEMATLE method can describe the direct and indirect effects of factors affecting the employment quality of college students. By analyzing the value of the centrality of the causal factors, it can be seen that "Government's employment recommendation service, government's employment subsidy, university enterprise cooperation, vocational planning and education of University, employer brand construction of enterprise, individual's employment will" are the direct factors that affects the employment quality of college students, and the vocational planning education in colleges and universities is the key and weak link, and it's also a priority for improvement.

The ISM method can be used to construct a multi-level hierarchical model that affects the employment quality of college students. The model is used to obtain the first-level surface elements, the second-level middle-level elements, and the third-level deep-level elements. It makes up for the problem of insufficient description of the operation mechanism of the DEMATEL method.

\section{B. Countermeasures}

In DEMATEL'S analysis, the countermeasures to improve the employment quality of college students can be considered as follows:

Straighten out the transfer relationship among the elements of college students' employment quality and highlight the work of key elements. In the cause factors of colleges and universities such as government employment recommendation service, employment subsidies of the government, cooperation between colleges and universities and career planning education in colleges and universities, corporate employer brand construction, employment intention for reasons of personal factors, colleges and universities of professional skill training, enterprise post development space and employment factors for results compatible degree, career planning education has the highest center degree. The social investment of causes and factors should get more support, especially in the education of college students' career planning, and the construction planning, investment guarantee and evaluation of this work should be focused on the deployment.

Expand the breadth and depth of school-enterprise cooperation. University-enterprise cooperation has been taken seriously, but most of the colleges and universities pay all attention in teaching cooperation, just practice in a few enterprises cooperation and orders. The cooperation form is single. through the analysis we can find that the reason degrees and center degrees of university-enterprise cooperation in university overlap, which suggests that the influence of university-enterprise cooperation is close to zero. It is known as the root cause of factors influencing the quality of university students' employment. 
University-enterprise cooperation should not only improve the quantity and quality of cooperation, but also explore the depth of cooperation content. How to highly integrate the supply chain of recruitment, cultivation and employment talents with the supply chain of products and services of enterprises, so as to exert the systematic effect of $1+1>2$.

In the ISM analyse, the countermeasures to improve the employment quality of colleges students can be considered as follows:

Enhance the investment of surface elements that affect the quality of college students' employment. Employment subsidies from the government, career planning and education in colleges and universities, and employer brand construction in enterprises have a direct impact on the improvement of employment quality of college students.

The career planning education in colleges and universities makes the life planning of colleges students more scientific. The enterprise employer brand is an effective way to improve the recruitment efficiency and avoid the overload of recruitment information.

Grasp both technical skills training and workplace adaptation training. Vocational skill training and workplace fitness are secondary influencing factors for the improvement of college student employment quality. The construction effect of the two factors is directly transmitted to the surface layer. In the talent cultivation of universities, academic education is always emphasized, and a single technical skill training is missing. And even if carried out vocational skills training, this also keeps university students in the technical level to meet the needs of jobs. In the workplace the intersection of people and technology not just technology is important. Outside of the workplace training is particularly important, right now, the work of college students is less, you will experience chance form is single, no system to adapt to training in the workplace, enhanced technical skills training and workplace adaptation training will help to amplify the effects of surface element inputs.

Finally, the employment recommendation service of the government, school-enterprise cooperation of colleges and universities, the job development space and employment intention of enterprises have profound and long term influences on the employment quality. Government as commended in the service platform construction should combine enterprise talent demand and college students' employment demand as "highway". University enterprise cooperation as "turbocharger" can make the talent training more targeted and efficient. Enterprise post space is like a "highway road signs" to guide the university students' employment. Strong implementation of these elements influence the deeper level of college students employment quality sound and rapid ascension [20].

It is effective to use the integrated DEMATEL / ISM method to analyze the influencing factors of the employment quality of college students, which can deeply explore the key factors of improving the employment quality of college students, and can explain the mutual influence and hierarchical relationship among these factors reasonably, and can provide a priority improvement path for improving the employment quality of college students. However, the comprehensive influence matrix maybe fail because of experts' preferences and unstable objectivity when the influence matrix is constructed with the integrated DEMATEL / ISM method, so, it needs to be further explored in the field of the expression of expert judgments, evaluation scales, and processing methods of the impact matrix. 


\section{ACKNOWLEDGMENT}

This work in the paper was supported by Anhui Provincial Quality Engineering Key Teaching Research Project (2017jyxm0628), Anhui Province Outstanding Talent Training Project (gxyqZD2018100), School-level of key Humanities Project (Wzyrwzd201704) \& the Project of industry university research fund in Anhui Province (2015-0437).

\section{REFERENCES}

[1] Pietro,C.D.and Cutillo,A.(2006),University Quality and Labour Market Outcomes in Italy , Labour,20(1),37-62.

[2] Kontas Mavromaras et aL.(2010), Job Mismatches and Labour Market Outcomes : Panel Evidence on Australian University Graduates,IZA.

[3] Dai M ,Wang Z C. The Job-match Quality of University Graduates in China $[\mathrm{J}]$. Research in Educational Development, 2014(3): 42-48.

[4] Max Research Institute. Blue book on Employment: 2019 report on the employment of Chinese college students $[\mathrm{M}]$. Beijing: Social Science Literature Press,2019:124-126.

[5] Wu X Z, Dong S Q ,College Graduates' Employment Quality Evaluation Elements and its System Builing g [J]. Science \& Technology Progress and Policy, 2017, 34(4): 140-144.

[6] W u X Z. Design of comprehensive evaluation index system for college students' Employment Quality [J]. Statistics \& Decision, 2017, (22): 68-71.

[7]Zhao M. Research on the countermeasures to improve the employment quality of college students in China [J]. Jiangsu Higher Education, 2019, (10): 67-72.

[8]Zhang C X. Influencing factors and Countermeasures of
College Students' Employment Quality [J]. Continue Education Research, 2019, (3): 69-71.

[9]Yano S T,Li N. Research on the policy system of high quality and full employment for College Students [J]. Henan Social Sciences, 2021, 29(6): 119-124.

[10] Altuntas S, Dereli T. A novel approach based on DEMATEL method and patent citation analysis for prioritizing a portfolio of investment projects. Expert Systems with Applications, 2015, 42(3): 1003-1012.

[11] Zhang L, Zhou D Q, Gao Y, et al. The evaluation method of civil cities based on DEMATEL and Choquet integral. Science Research Management, 2012, 33(9): 71-77.

[12] Bai C G, Sarkis J. A grey-based DEMATEL model for evaluating business process management critical success factors. International Journal of Production Economics, 2013, 146(1): 281-292.

[13] Wu H H, Chang SY. A case study of using DEMATEL method to identify critical factors in green supply chain management. Applied Mathematics and Computation, 2015, (256): 394-403.

[14] Hsu C W, Kuo T C, Chen S H. Using DEMATEL to develop a carbon management model of supplier selection in green supply chain management. Journal of Cleaner Production, 2013, 56: 164-172.

[15] Jeng J F. Generating a causal model of supply chain collaboration using the fuzzy DEMATEL technique. Computers \&Industrial Engineering, 2015, (87): $283-295$

[16] Uygun O, Kacamak H, Kahraman U A. An integrated DEMATEL and fuzzy ANP techniques for evaluation and selection of outsourcing provider for a telecommunication company. Computers \& Industrial Engineering, 2015, 86: 137-146.

[17] Wu H H, Tsai Y N. A DEMATEL method to evaluate 
the causal relations among the criteria in auto spare parts industry. Applied Mathematics and Computation, 2011, 218(5): 2334-2342.

[18] Sun Y H, Han W, Duan W C. Review of research progress on DEMATEL algorithm for complex systems. Control and Decision, 2017, 32(03): 385-392.

[19] He Y G, Zhang Q P. Construction and analysis of college student employment system based on ISM model. Science and Technology and Management, 2011, 13(04): 26-30.

[20] Zhao Dongmin. Employment Quality Evaluation and Improvement Path Design for College Students in the Context of New Economy. University of Jinan, 2019.

\section{About the authors:}

1. Wei Wang (1983-), male,from Wuhu city, Anhui Province,China. His research field is system engineering and decision-making.

2. Jian Liu(1984-), female, from Ma'anshan city, Anhui Province, China. Her research field is public affairs management.

3. Shubing Qiu (1980-), male, from Weifang city, Shandong Province, China. His research field is macroeconomic management.
Creative Commons Attribution License 4.0 (Attribution 4.0 International, CC BY 4.0)

This article is published under the terms of the Creative Commons Attribution License 4.0 https://creativecommons.org/licenses/by/4.0/deed.en_US 